\title{
Review of agricultural spraying technologies for plant protection using unmanned aerial vehicle (UAV)
}

\author{
Haibo Chen ${ }^{1,2}$, Yubin Lan ${ }^{2,3^{*}}$, Bradley K Fritz ${ }^{4}$, W. Clint Hoffmann ${ }^{5}$, Shengbo Liu ${ }^{2,3}$ \\ (1. Experimental Basis and Practical Training Center, South China Agricultural University, Guangzhou 510642, China; \\ 2. National Center for International Collaboration Research on Precision Agricultural Aviation Pesticides Spraying Technology, \\ Guangzhou 510642, China; \\ 3. College of Electronic Engineering, South China Agricultural University, Guangzhou 510642, China; \\ 4. USDA-ARS Aerial Application Technology Research Unit, College Station, TX 77845, USA; \\ 5. Prology Consulting, College Station, TX 77845, USA)
}

\begin{abstract}
With changing climate and farmland ecological conditions, pest outbreaks in agricultural landscapes are becoming more frequent, increasing the need for improved crop production tools and methods. UAV-based agricultural spraying is anticipated to be an important new technology for providing efficient and effective applications of crop protection products. This paper reviews and summarizes the status of the current research and progress on UAV application technologies for plant protection, and it discusses the characteristics of atomization by unmanned aircraft application systems with a focus on spray applications of agrichemicals. Additionally, the factors influencing the spraying performance including downwash airflow field and operating parameters are analyzed, and a number of key technologies for reducing drift and enhancing the application efficiency such as remote sensing, variable-rate technologies, and spray drift models are considered. Based on the reviewed literature, future developments and the impacts of these UAV technologies are projected. This review may inspire the innovation of the combined use of big data analytics and UAV technology, precision agricultural spraying technology, drift reduction technology, swarm UAV cooperative technology, and other supporting technologies for UAV-based aerial spraying for scientific research in the world.
\end{abstract}

Keywords: UAV, plant protection, spraying technology, drift reduction, pesticide efficacy, spraying model, big data analytics DOI: $10.25165 /$ j.ijabe.20211401.5714

Citation: Chen H B, Lan Y B, Fritz B K, Hoffmann W C, Liu S B. Review of agricultural spraying technologies for plant protection using unmanned aerial vehicle (UAV). Int J Agric \& Biol Eng, 2021; 14(1): 38-49.

\section{Introduction}

According to the "Agriculture in 2050 Project", the world population will reach about 10 billion by 2050 . Consequently, food production will require a $70 \%$ boost $^{[1]}$. However, with changing climate and farmland ecological conditions, pest outbreaks in agricultural landscapes are becoming more frequent, increasing the threats to crop production ${ }^{[2-4]}$. The use of pesticides is an integral part of modern agriculture and contributes to the productivity and quality of most agricultural products ${ }^{[5]}$. It is estimated that the use of agrochemicals prevents a loss of up to $45 \%$ of the world's food supply ${ }^{[6]}$. The main spraying equipment used in conventional farming is the manual air-pressure and battery-powered knapsack sprayers. The World Health Organization (WHO) estimated one million cases of ill effects

Received date: 2020-02-04 Accepted date: 2021-01-12

Biographies: Haibo Chen, $\mathrm{PhD}$, Associate Professor, research interest: agricultural mechanization, automation and information, Email: huanongchb@, scau.edu.cn; Bradley K Fritz, PhD, Agricultural Engineer, research interest: agricultural aviation application, Email: brad.fritz@ars.usda.gov; W. Clint Hoffmann, $\mathrm{PhD}$, Agricultural Engineer, research interest: agricultural aviation application, Email: clint.hoffmann@gmail.com; Shengbo Liu, Master candidate, research interest: precision agriculture aviation technology and equipment, Email: 1sbyx@stu.scau.edu.cn.

*Corresponding author: Yubin Lan, $\mathrm{PhD}$, Professor, research interest: precision agricultural aviation application. International Laboratory of Agricultural Aviation Pesticide Spraying Technology (ILAAPST), South China Agricultural University, Guangzhou 510642, China. Tel: +86-20-85281421, Email: ylan@scau.edu.cn. when spraying the pesticides in the crop filed manually. In addition, these conventional sprayers can cause major pesticide losses and environmental harm. In order to reduce humans' and environmental harm, as well as to deal with labor shortage, spraying mechanization is imperative. Agricultural aerial spraying, both manned and unmanned, is often the most economical and rapid method for providing efficient and effective applications for crop pest control, allowing for rapid responses to sudden pest outbreaks ${ }^{[7]}$. Moreover, it can cover a large field without destruction to the crop or soil physical structure, compared with ground plant-protection machinery, which is very important.

The manned aerial application was first used in the United States in 1921, using surplus aircraft from World War I. Today's aerial application systems are specially-built aircraft that incorporates an array of modern technologies, such as GPS positioning, automated flow control, and precision application systems. While US cropping systems tend to be large areas, Asian cropping systems are smaller in scale, more geographically complex, and vary greatly from region to region. The need to apply crop protection and production products effectively under these conditions has resulted in the rapid development and adoption of UAVs in $\mathrm{Asia}^{[8,9]}$. Compared to manned aerial applications, UAV-based platforms are less expensive to own and operate and allow for lower altitude applications that can be more conveniently adapted to the small complex field plots across Asia's diversified crop planting zones and specialty crops cultivated on high slopes ${ }^{[10-13]}$. Moreover, UAVs can also perform site-specific farm management with high precision. 
With the increased demand for precision agriculture (PA) and smart farming, UAVs are going to play a crucial role in the development of the agricultural sector. According to the Association for Unmanned Vehicle Systems Inter-national (AUVSI), $80 \%$ of UAVs will be utilized for agricultural purposes in the near future. However, there are still some issues to overcome with UAV-based spraying technology, such as droplet drift and pesticide efficacy ${ }^{[14-20]}$. The new circumstances of modern agricultural construction are those making agriculture realize the goal of high yield, high quality, high efficiency, ecology and safety, realizing green consumption and sustainable development, and building resource-saving and environmentalfriendly agriculture. It is crucial for aerial application of pesticides to be environmentally protective and efficacious ${ }^{[21]}$, and new technologies are required for the effective delivery of pesticides and agrochemicals by using UAV. The status of the current research and progress on UAV-based spraying technologies for plant protection are reviewed and summarized here. Furthermore, some research challenges that need to be carefully taken into consideration in the future are projected. It is expected to provide references for scientific research and promote the development of plant protection UAV industry in the world.

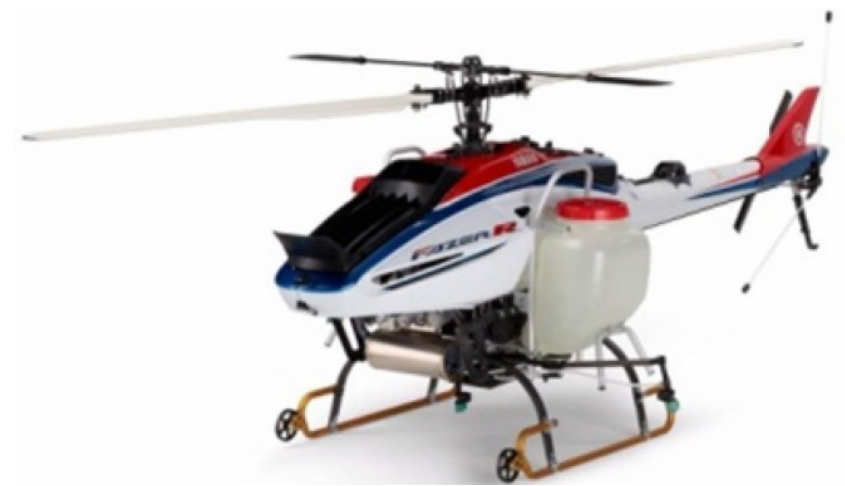

a. Yamaha's Fazer R, features a class-leading maximum $32 \mathrm{~L}$ agrochemical payload, allowing the spraying of $4 \mathrm{hm}^{2}$ without reloading chemicals or refueling

\section{Development histories and characteristics of atomization by unmanned aerial spraying system}

\subsection{Development histories of unmanned aerial spraying system}

In 1985, Yamaha initially launched the world's first agricultural UAV Model Rmax for pesticide application, which was an unmanned medium-scale helicopter with a $5 \mathrm{~kg}$ payload capacity. The company has also developed a series of unmanned helicopters (KG-135, YH300 and AYH3, etc.) (Figure 1a) for pesticide spraying over crop fields. Yamaha helicopters were adopted as a research platform by many countries around the world However, the export of Yamaha helicopters was banned in 2007 to protect their technology. Multi-rotor UAVs, including four, six and eight-rotor platforms (Figure 1b), have replaced helicopters as the most widely used UAV platforms for agricultural applications. In recent years, China has developed and implemented UAVs for crop protection ${ }^{[4,8,22,23]}$. UAV spraying technology and implementation have both advanced in Asia, but the technology and use have been adopted much more slowly by producers in North America and Europe ${ }^{[24]}$. UAV missions associated with carrying and dispersing pesticides are considered more hazardous than remote sensing missions.

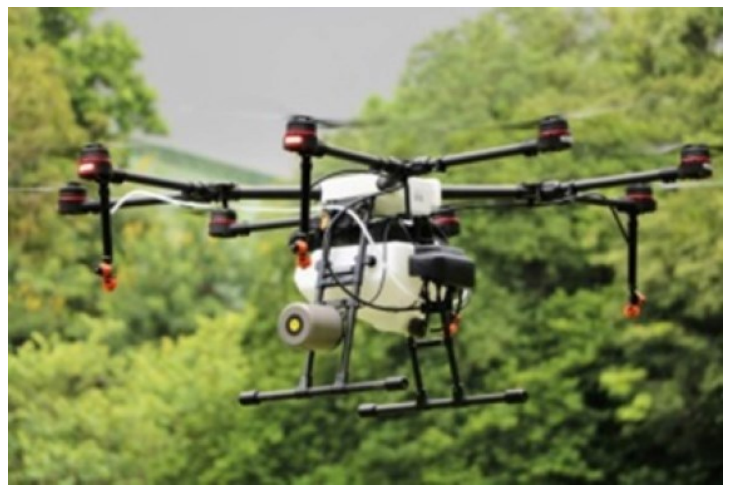

b. DJI's MG Series, eight rotors, $10 \mathrm{~kg}$ payload, $2.8-4 \mathrm{hm}^{2} / \mathrm{h}$, multi-aircraft control mode

Figure 1 Modern UAV spray systems

UAV spraying systems are increasing in size and complexity, with tank volumes increasing from 5 to $32 \mathrm{~L}$ and application rates varying from 1 to $30 \mathrm{~L} / \mathrm{hm}^{2}$. Numerous advanced technologies such as Global Positioning System (GPS) navigation, automatic path planning, automatic spraying systems, real-time kinematic (RTK) high-accuracy positioning, obstacle avoidance technologies, and pulse width modulation systems (PWM) have been adapted for use on multi-rotor drones, improving their operational stability, efficiency, accuracy and ease of operation ${ }^{[25-28]}$.

\subsection{Types and characteristics of agricultural UAVs}

There are a wide variety of UAV shapes, sizes, lifting capacities, and configurations ranging from fixed-wing to single and multi-rotor aircraft. The power systems of UAV can be electrical or fuel-powered. Electric-powered UAVs have flights lasting 10-45 $\mathrm{min}$ in duration, while fuel-powered systems can operate for $1-4+\mathrm{h}$. Most multi-rotor UAVs in current use are electric-powered. This type of UAV has a simple structure, convenient maintenance, and excellent flight stability and spray efficiency. Therefore, it has become a popular choice for UAV-based plant protection applications. Compared to expensive unmanned helicopters (the price of a Rmax of Yamaha is approximately one million dollars), multi-rotors UAVs are frequently used in plant protection in China, partly owing to their lower price (less than 20000 dollars) and mechanical simplicity.

\subsection{Characteristics of atomization by UAV}

2.3.1 Flow field and its distribution characteristics

Spraying low-volume agrichemicals using UAVs at low flight altitude differs from both conventional manned aerial applications and ground equipment-based applications ${ }^{[8]}$. The rotation of the rotor and the interaction of the air provide the necessary lift for the airframe, and they produce downward airflow that can assist the movement of spray droplets into the crop canopy, which can enhance deposition and reduce drift ${ }^{[29-31]}$. A strong eddy current field is therefore generated in the rotor flow field, and it presents a cone-like vortex ${ }^{[32,33]}$ (Figure 2). However, vortices that are generated by the rotor tips can cause pesticide droplets to be lifted above the aircraft, increasing the potential for drift. These effects have been the focus of numerous studies about the downwash flow field through the use of spatial quality balance, numerical analysis and computational fluid dynamics (CFD) simulations, a few of which are discussed in the following section.

Wang et al. ${ }^{[34]}$ and $\mathrm{Xu}$ et al. ${ }^{[35]}$ studied the spray flow field characteristics of a large-sized agricultural UAV (FR-200, Feirui Aviation Technology Co., Ltd, Jiangsu, China) using computational fluid dynamics (CFD). The results showed that the vertical velocity distribution of the downwash flow field was unsymmetrical. The vertical velocity increased and then decreased along the direction of the rotor at the spray boom 
location, and the velocity reached its maximum near $\mathrm{x} / \mathrm{R}=0.8$ (the direction in which the UAV flies forward was the negative direction of $\mathrm{x}$; and $\mathrm{R}$, radius of propeller). The width of the rotor wash airstream at the plant canopy surface was increased with the decreasing application height, and the better flight height was $4 \mathrm{~m}$. The boom of the UAV should be installed in the area with $\mathrm{z}$ (the direction in which the UAV rises is the positive direction of $\mathrm{z}$ ) from -1.50 to $-2.00 \mathrm{~m}$ and $x$ (the direction in which the UAV flies forward was the positive direction of $x$ ) from -0.50 to $0.50 \mathrm{~m}$. Zhang et al. ${ }^{[36]}$ studied the downwash distribution of a single-rotor UAV (N-3, Nanjing Research Institute for Agricultural Mechanization Ministry of Agriculture, China) by CFD simulation and experimental verification. The downwash covered a circular area of radius of approximately $3.0 \mathrm{~m}$ (approximately 2 times the rotor radius size) effectively with $0.5 \mathrm{~m} / \mathrm{s}$ as the boundary velocity, which provided a reference to determine the aerial spraying width. The simulation and experimental results both showed that the downwash velocity change varied as the radial distance increased, first increasing and then decreasing. The highest downwash velocity occurred in the area contained within $25 \%$ to $75 \%$ of the rotor radius, and as the longitudinal altitude increased, the downwash velocity displayed a local minimal interval and a local maximum interval. Chen et al. ${ }^{[37]}$ used a uniaxial, single-rotor, electric, unmanned helicopter as an example to study the effect of the wind field in the $X$ (the direction parallel to the flight), $Y$ (the direction perpendicular to the flight), and $Z$ (the direction perpendicular to the ground) directions below the rotor. The results revealed that the effects of the wind field in the $Y$ and $Z$ directions on the droplet deposition in the effective spray area were significant and extremely significant, respectively, and only the wind field in $Z$ direction had a significant effect on the uniformity and penetrability of the droplet deposition in the effective spray area. The wind speed in $Y$ direction below the rotor had a significant effect on the droplet drift.

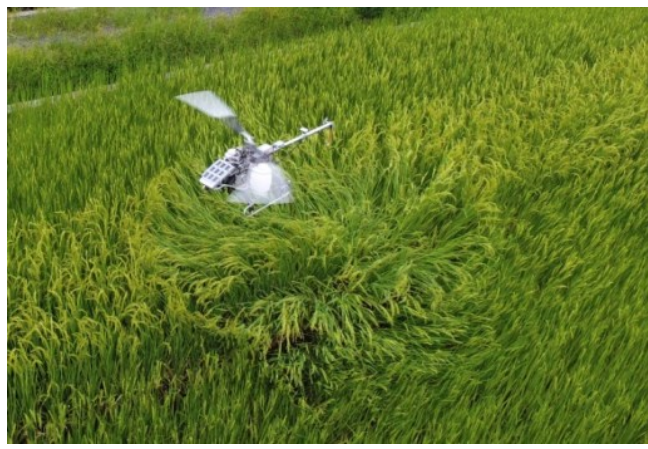

a. Vortex of single-rotor

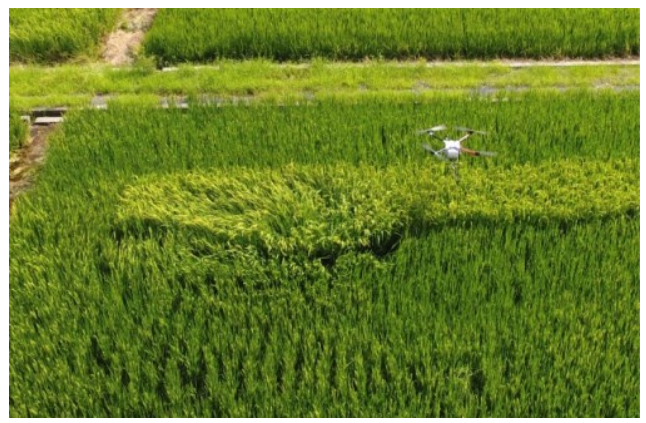

b. Vortex of multi-rotor

Figure 2 Features of the airflow for the UAV rotor

Regarding the downwash airspeed, Yang et al. ${ }^{[38]}$ found that the maximum velocity value of the vertical downwash flow was close to $10 \mathrm{~m} / \mathrm{s}$ by using both numerical simulations and experimental verification for a six-rotor UAV (SKL-5, Xi'an Wideworldz Aviation Technology Co., Ltd, China). Tan et al. ${ }^{[39]}$ also reported a maximum downwash airspeed of $10.8 \mathrm{~m} / \mathrm{s}$.

\subsubsection{Effects of the flow field on the spray performance}

The downward airflow generated by the UAV rotors helps to increase the penetrability of the droplets into the canopy to improve pesticide distribution; there is a higher deposition on the upper layer and the under layer than that in traditional spraying ${ }^{[0,41]}$, and the droplet coverage rates on the canopy and the distribution uniformity are the best ${ }^{[42]}$.

Furthermore, the airflow impact of the drone rotors increases the risk of spraying drift (Figure 3). The average diameter of the droplets sprayed by agricultural drones is always smaller than that of fixed-wing aircraft ${ }^{[43]}$. The anti-drift performances of the nozzles at different locations of the spray boom are different, and the spray drift of the nozzles at both ends of the boom is serious because of the rotor tail vortex. The dispersion of spray droplets from the nozzle directly below the fuselage is increased due to the blocking effect ${ }^{[34,35]}$. To reduce the drift of the droplets, the length of the boom should not be larger than the diameter of the rotor. Due to the influence of the lower washing flow field, the droplet distribution had periodic pulsation and uneven spatial and temporal distribution. Tang et al. ${ }^{[4]}$ measured the droplet movement and deposition for the downwash flow field over the crop at different rotor rotation speeds in an octocopter using high-speed particle image velocimetry (PIV). The downwash velocity could not only change the deposition zone of the droplets but also influence their distribution. The increase of the downwash velocity would increase the deposition uniformity of the droplets. The nozzle position in the downwash flow field could also influence the deposition of the droplets. When the transverse distance between the nozzle and its nearby rotors increased, the relative deposition near the downwash flow of the rotors increased simultaneously. However, the distance between the deposition peak and the nozzle stayed constant. The initial spray angle of the nozzle was not influenced by the transverse distance between the nozzle and its nearby rotors.

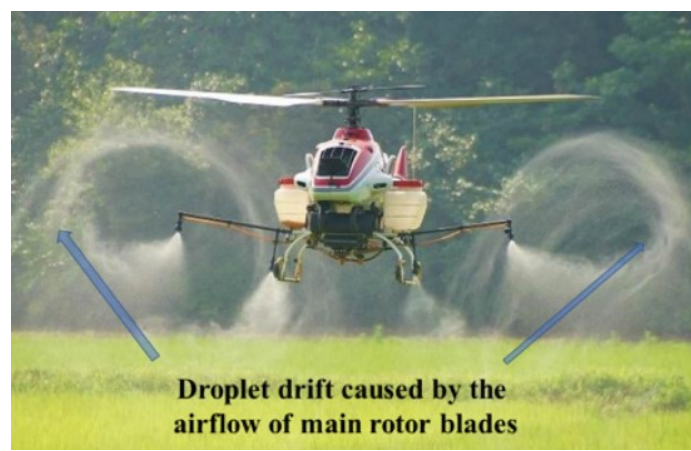

Figure 3 Droplet drift caused by the airflow of the primary rotor blades of $\operatorname{Rmax}^{[45]}$

Regarding the relationship between the UAV flight parameters (height, speed, etc.) and the movement state of the droplets under the rotor airflow, Wang et al. ${ }^{[46]}$ revealed that regardless of the flight direction and the height and the crosswind, all these factors influenced the droplet deposition distribution by weakening the intensity of the downwash airflow field in the direction perpendicular to the ground. Yang $\mathrm{F}$ et al. ${ }^{[47,48]}$ proposed an approach to researching the influence of the downwash and windward airflow on the motion distribution of the droplet group for the multi-rotor UAV in a hovering state, and they established the three-dimensional two-phase flow model for a six-rotor UAV 
under a $3 \mathrm{~kg}$ load. Yang et al. ${ }^{[49]}$ explored the influence of the UAV rotor downwash airflow on the spray width by fluid simulation. The results revealed that the velocity discrepancy from the middle to the outside of the downwash airflow led to an expanding trend in the airflow and thus an expansion of the spray width. The spray width was basically proportional to the flying height. The curling airflow around the rotor led to two peak values for the droplet deposition within the spray width, which might also lead to an increase in the spray drift. Zheng et al. ${ }^{[50]}$ simulated and numerically analyzed the downwash flow fields of a multi-rotor UAV intended for practical spraying operations at different hovering heights by establishing a full-scale physical model. It was concluded that with an increased hovering height, the ground effect was reduced and the minimum current velocity increased initially and then decreased. During practical operation of the JF01-10 UAV (Viga Intelligent Technology Co., Ltd., Beijing) using a hovering height of $3 \mathrm{~m}$ was likely to be appropriate. Shi et al. ${ }^{[51]}$ found that the widest deposition range of droplets reached $12.8 \mathrm{~m}$ at a flight speed of $3 \mathrm{~m} / \mathrm{s}$ and an altitude of $1.5 \mathrm{~m}$. Wen et al. ${ }^{[52]}$ used CFD to simulate the downwash flow field of a quad-rotor drone, successfully capturing the horseshoe-shaped vortices at a flight speed exceeding $5 \mathrm{~m} / \mathrm{s}$, and they found that the flight altitude had no direct influence on the horseshoe vortices. Using a wind tunnel test and numerical simulation, they also revealed that the droplet drifts and the increase in the spray amplitude were caused by the increase in the flight speed and the altitude of the quad-rotor drone. A smaller vertical height for the spray rod from the rotor resulted in a larger drift of droplets behind the fuselage and a larger spray amplitude. Moreover, a smaller distance between the nozzle and rotor tip resulted in a larger droplet drift behind the fuselage and a larger spray amplitude.

\section{Research progress of UAV-based spraying technologies for plant protection}

\subsection{UAV-based remote sensing for plant protection}

One of the fastest growing uses of UAVs in agriculture is to obtain images of crops and crop conditions from these aerial platforms using a wide variety of cameras and sensors. UAVs have been developed in support of precision agriculture to carry out remote sensing and pesticide spraying missions with high temporal (e.g., daily acquisition) and high spatial (e.g., centimeter) resolutions ${ }^{[10]}$. There are three general problems with the remote sensing of weeds, insects, and diseases. The first is the identification accuracy for the disease, pest, or plant of interest. The second is how to monitor a field when the outbreak locations are spatially random. Lastly, the third problem is how to automate the process to analyze hundreds to thousands of images, each covering a small area ${ }^{[53]}$. With technological advances in big data, image processing and deep learning, UAV imagery acquired by digital cameras or hyperspectral sensors could promote applications of UAV-based remote sensing technologies for pest detection and pest identification in prescription variable-rate operations. The refereed literature in remote sensing is extensive and rapidly advancing ${ }^{[54-57]}$; therefore, an in-depth review is beyond the scope of this manuscript, so only a few of the more common uses will be discussed.

UAVs provide a unique platform for remote sensing in crop fields due to their slow flight speeds and low altitudes. They are generally more efficient and flexible than manned agricultural airplanes, which often cannot provide images at both low altitudes and low speeds to capture high-quality images ${ }^{[58,59]}$. With the development of various small-sized, lightweight, high-precision remote sensing sensor devices, UAV-based remote sensing technologies have greatly expanded the application range for monitoring crops to provide high-resolution data from UAV-acquired images (Table 1). These systems are expected to be an important part of the increased integration of remotely-sensed data into precision agriculture.

Table 1 Applications of UAV remote sensing for plant protection from the literature in the past three years

\begin{tabular}{|c|c|}
\hline UAV remote sensing applications & Source \\
\hline $\begin{array}{l}\text { Recognition of infected olive groves based on UAV } \\
\text { imagery }\end{array}$ & Psirofonia et al. ${ }^{[60]}$ \\
\hline $\begin{array}{l}\text { Detection of potato beetle damage using UAV } \\
\text { multispectral imagery }\end{array}$ & Hunt and Rondon ${ }^{[61]}$ \\
\hline $\begin{array}{l}\text { Detection of flavescence dorée grapevine disease using } \\
\text { UAV multispectral imagery }\end{array}$ & Albetis et al. ${ }^{[62]}$ \\
\hline $\begin{array}{l}\text { Detecting Fusarium wilt in radishes using UAV RGB } \\
\text { imagery }\end{array}$ & Ha et al. ${ }^{[63]}$ \\
\hline Identification of soybean foliar diseases using UAV images & Tetila et al. ${ }^{[64]}$ \\
\hline Silybum marianum detection on UAV multispectral images & Alexandridis et al. ${ }^{[65]}$ \\
\hline $\begin{array}{l}\text { Using UAVs for precision pest control of possums } \\
\text { (Trichosurus vulpecula) }\end{array}$ & Morley et al. ${ }^{[66]}$ \\
\hline $\begin{array}{l}\text { Weed mapping using UAV multispectral imagery or } \\
\text { UAV imagery }\end{array}$ & $\begin{array}{l}\text { Castaldi et al. }{ }^{[67]} \\
\text { Tamouridou et al }{ }^{[68]} \\
\text { Pantazi et al. }{ }^{[69]} \\
\text { Sa et al. }{ }^{[70]} \\
\text { De Castro et al }{ }^{[71]} \\
\text { Huang et al. }{ }^{[72-74]}\end{array}$ \\
\hline Weed classification using UAV images & $\begin{array}{l}\text { Lottes et al. }{ }^{[75]} \\
\text { Wang et al. }\end{array}$ \\
\hline $\begin{array}{l}\text { Identification of diseased empty rice panicles based on } \\
\text { the Haar-like features of UAV optical images }\end{array}$ & Wang et al. ${ }^{[77]}$ \\
\hline $\begin{array}{l}\text { Detection of spider mite-infested cotton using UAV } \\
\text { multispectral imagery }\end{array}$ & Huang et al. ${ }^{[78]}$ \\
\hline $\begin{array}{l}\text { Plant pest surveillance in vineyards and crops using } \\
\text { UAV-based hyperspectral and spatial data }\end{array}$ & Vanegas et al. ${ }^{[79]}$ \\
\hline $\begin{array}{l}\text { Evaluation of rice sheath blight based on UAV visible } \\
\text { light and multispectral remote sensing }\end{array}$ & Zhao et al. ${ }^{[80]}$ \\
\hline $\begin{array}{l}\text { Monitoring and classification of citrus Huanglongbing } \\
\text { based on UAV hyperspectral remote sensing }\end{array}$ & Lan et al. ${ }^{[81]}$ \\
\hline $\begin{array}{l}\text { Spatio-temporal monitoring of wheat yellow rust using } \\
\text { UAV multispectral imagery }\end{array}$ & Su et al. ${ }^{[82]}$ \\
\hline
\end{tabular}

\subsection{Variable-rate spray technology}

During real agricultural production, the severity of plant diseases and insect pests varies in different locations. To reduce pesticide waste, pesticides should be applied according to the severity of the pests, insects and weeds, thus variable-rate spray technology has developed rapidly in recent years. In the context of aerial applications, variable-rate control can simply mean terminating the spray over field areas that do not require inputs, terminating the spray near pre-defined buffer areas determined by global positioning, or applying multiple rates to meet the variable needs of the crop.

Variable-rate spray technology is one of the key technologies used in precision aerial spraying ${ }^{[83]}$. The two components in a variable-rate aerial application system are GPS and the variable flow control system. UAVs have high control precision and fast response speed when using a variable spray system. Zhu et al. ${ }^{[25]}$ developed a pulse width modulation (PWM) controller for a UAV precision agriculture sprayer, and the relatively strong correlation between flow amount and duty cycle (the determination coefficients was 0.9636 ) indicated that the PWM controller had promised for precision spraying. Wang et al ${ }^{[84]}$ developed the ground measurement and control unit by LabWindows/CVI. The 
pressure and flow rate of the spraying system was remotely controlled through a wireless data transmission module. In this way, variable-rate spraying adjustment for plant protection UAV was achieved. Wang et al. ${ }^{[85]}$ developed a precision spraying control system for UAV based on image recognition, which used an algorithm to classify and identify the crop areas and non-crop areas in aerial images of the field, and it controlled the nozzle based on the recognized results to achieve precise spraying with plant recognition accuracy reaching up to $76.56 \%$. Wang et al. ${ }^{[86]}$ designed a dynamic spraying control system and method for plant protection UAV, by which the flow rate was able to match the operating speed accurately and automatically with multi-sensor fusion technology. The results showed that when the operating speed was changed from 0.8 to $5.8 \mathrm{~m} / \mathrm{s}$, the average deviation between the practical flow rate and the theoretical flow rate was only $1.9 \%$. Wen et al. ${ }^{[87]}$ designed a variable spray system for unmanned aerial vehicles based on proportional-integral-derivative (PID) and PWM control. The test results showed that the system could achieve rapid and accurate changes of flow according to prescription map information, effectively reducing herbicide use and enhancing the effective use of the chemical. Lian et al. ${ }^{[88]}$ designed a precision variable-rate spray system based on a single-chip microcomputer and micro diaphragm pump that can control the flow rate of the pump in real-time with the changes of the operating state. The results of the response test showed that the average response time of the present system was $0.16 \mathrm{~s}$, and the average pump flow stabilization time was $0.54 \mathrm{~s}$.

To establish a dynamic model between operating factors, such as the speed and height and the rate of application, Wen et al. ${ }^{[89]}$ designed a plant protection UAV variable spray system that integrated neural network-based decision making into the dynamic UAV spray operations. The outdoor tests showed that the error between the predicted droplet deposition and the actual droplet deposition was less than $20 \%$, and a variable spray operation was performed under different conditions.

In practical application, Campos et al. ${ }^{[90]}$ developed a variable rate application technology based on prescription maps for UAV spray application in vineyards. The spraying system was able to modify the working parameters (pressure) in real-time in order to follow the prescription map. The results indicated that site-specific management resulted in a $45 \%$ reduction of the application rate when compared with conventional spray application. Hunter et al. ${ }^{[1]}$ combined weed mapping and sprayers into a UAV integrated system (UAV-IS) to implement site-specific pest management. The results showed that it can reduce pesticide use. However, the impact on weed control efficacy would depend on weed distribution and weed morphology.

\subsection{Operation parameters for the UAV spraying system}

The operating parameters of plant protection UAVs have a large impact on spraying drift and deposition effectiveness. Many researchers focus on exploring the factors that impact spray deposition and downwind movement with the goal of optimizing the operational parameters of different UAV and crop type combinations.

3.3.1 Effects of the operating parameters on the spraying performance

Zhang et al. ${ }^{[92]}$ evaluated the aerial spraying drift on a UAV (N-3, Nanjing Research Institute for Agricultural Mechanization Ministry of Agriculture, China) using simulations and experiments; the flight speed was $3 \mathrm{~m} / \mathrm{s}$, the crosswind velocities were $1 \mathrm{~m} / \mathrm{s}$, $2 \mathrm{~m} / \mathrm{s}$ and $3 \mathrm{~m} / \mathrm{s}$, and the flight heights were $5 \mathrm{~m}, 6 \mathrm{~m}$ and $7 \mathrm{~m}$.
The results showed that the effect of the crosswind velocity was greater than that of the aerial spraying height on droplet drift. The droplet drift only occurred downwind of the spraying field; and because the crosswind velocity was 1-3 $\mathrm{m}, 8-10 \mathrm{~m}$ buffer zones should be considered downwind from the spraying field for safe aerial spraying. Zhou and $\mathrm{He}^{[93]}$ performed the spraying simulation and experiments on UAV with the water sensitive papers (WSPs) fixed on the five tea trees in the spraying region. The results demonstrated that the droplet distribution uniformity was improved while the droplet density and percentage of the spray coverage decreased as the flight velocity increased. Zhang et al. ${ }^{[94]}$ investigated the influences of the droplet size, droplet velocity, spray angle, flow rate, the height of the nozzle, wind speed and growth stage of the plant on deposition at various parts in a wind tunnel. The results indicated that the distribution of the spray was influenced by the droplet size, release height, wind speed and growth stage. In addition, the spray angle, sheet velocity, flow rate and plant type had no significant effect on the spray distribution. Chen et al. ${ }^{[12]}$ evaluated the effective spraying width of single-rotor and multi-rotor plant protection UAVs using the evaluation methods of the droplet density and $50 \%$ effective deposition amount method with different flight parameters. The test results showed that an evaluation method with $50 \%$ effective deposition should be chosen by the plant protection UAVs with relatively larger droplet size, and the droplet density evaluation method should be chosen for plant protection UAV with relatively smaller droplet size. Zheng et al. ${ }^{[95]}$ tested pesticides spray effects for corn at different growth stages using a six-rotor UAV with different heights and velocities. Mathematical models of droplet-penetrating coefficients with operational parameters were established at all growth stages, and the determination coefficients $\left(R^{2}\right)$ of all models were greater than 0.90 with average relative errors within $20 \%$. Wang et al. ${ }^{[96]}$ evaluated spray drift characteristics by using a fuel-powered single-rotor UAV at different working heights and velocities. The results showed that the influence of the wind speed on the spray drift was greater than that of the flight height and flight velocity of the UAV at an average temperature of $31.5^{\circ} \mathrm{C}$, average relative humidity of $34.1 \%$, and a $15 \mathrm{~m}$ buffer zone that should be considered downwind from the spraying field for safe aerial spraying. Liao et al. ${ }^{[97]}$ explored the application efficiency and cost with different operation parameters for maximizing the efficacy and efficiency in UAV-based spray applications on cotton.

\subsubsection{Optimum application parameters for plant protection UAV}

In optimizing the operating parameters of plant protection UAVs, researchers have explored different types of UAVs and crops (Table 2). Kang et al. ${ }^{[98]}$ analyzed the flowing and spraying characteristics of the spray droplets by the primary rotor downwash by setting the application conditions at a flight altitude of $3 \mathrm{~m}$, the diameter of the primary rotor at $3.1 \mathrm{~m}$, the boom length at approximately $2.8 \mathrm{~m}$, and the spraying volume at $8 \mathrm{~L} / \mathrm{hm}^{2}$. The results showed that the boom with a $10^{\circ}$ tilt angle and spraying height of $3 \mathrm{~m}$ was the optimum setup for aerial pesticide application. The nozzle position for minimizing the scattering loss of spray droplets due to the vortex phenomenon at both ends of the main rotor was approximately $10 \mathrm{~cm}$ from the end of the main rotor. Zhang et al. ${ }^{[99]}$ studied the influence of the application parameters of the unmanned aircraft on the droplet deposition, showing that the optimum application parameters for a UAV (WPH 642) were a flight altitude of $2 \mathrm{~m}$ and a flight speed of $1.5 \mathrm{~m} / \mathrm{s}^{2}$. Qin et al. ${ }^{[17]}$ explored the effect of spray droplet deposition from 
applications using a UAV (N-3, Nanjing Research Institute for Agricultural Mechanization Ministry of Agriculture, China) on late-season maize at different application heights and an effective spraying swath width, and they showed that a $7 \mathrm{~m}$ working height and a $7 \mathrm{~m}$ spraying swath should be chosen for spraying pesticides. Qin et al. ${ }^{[18]}$ reported that the deposition and distribution of droplets in the late stage of rice growth were closely related to the operational height and velocity of crop spraying as executed by a single-rotor UAV. When the flight height was $1.5 \mathrm{~m}$ and the flight speed was $5 \mathrm{~m} / \mathrm{s}$, the droplet deposition in the lower layer was maximized, and the droplets exhibited the most uniform distribution (coefficient of variance $(\mathrm{CV})=23 \%$ ). Qin et al. ${ }^{[100]}$ also investigated the spraying parameters of a multi-rotor UAV using the central combination test and design concept of Box-Behnken based on the single-factor test, and the optimal combination of spraying parameters (flight height of $2.0 \mathrm{~m}$, flight speed of $3.7 \mathrm{~m} / \mathrm{s}$ and nozzle flow rate of $7.17 \mathrm{~mL} / \mathrm{s}$ ) was obtained and verified. Moreover, Qin et al. ${ }^{[42]}$ studied the impact of the UAV (UAV N-3) spraying parameters (different working height and different spraying concentrations) on the deposition of droplets on the wheat canopy. The experimental results showed that the impact of the spraying height on the distribution of droplets on the wheat upper layer was quite significant. When the flight height was $5.0 \mathrm{~m}$ and the flight speed was $4 \mathrm{~m} / \mathrm{s}$, the droplet coverage rate on the lower wheat layer was the largest, at $45.6 \%$ of that on the upper layer, and the distribution of the droplets was the most uniform, with a coefficient of variation of $33.13 \%$. Woldt et al. ${ }^{[101]}$ modified the traditional aerial application testing procedures for small UAV spray test research, and they evaluated two different, commercially available UAV systems for operational techniques and application system efficacy under dynamic field conditions. The results from the initial testing protocols indicated that the factory-supplied systems were quite different in design and implementation, with spray test results that reflected this difference in design, in both the deposition and spray swath. With the advent of unmanned aerial application systems and the unique characteristics of the integrated aircraft and application systems, there is a very real need for the development of standardized small UAV system-testing procedures. Lou et al. ${ }^{[19]}$ used tests to reveal that the droplet distribution and drift were satisfactory for UAV spraying on cotton at a flight altitude of $2 \mathrm{~m}$. Hunter et al. ${ }^{[102]} \mathrm{did}$ field tests to study coverage and drift potential associated with nozzle and speed selection for herbicide applications using an unmanned aerial sprayer. Results suggested that air-induction flat-spray and turbo air-induction flat-spray nozzles and an application speed of $3 \mathrm{~m} / \mathrm{s}$ provided an adequate coverage of target areas while minimizing off-target movement risk.

In exploring the effect of plant protection by UAV-based spray for fruit trees and its application prospects, Giles et al. ${ }^{[103]}$ evaluated the spray deposition and performance of a petrol-powered helicopter (Rmax, Yamaha Motor Co. USA, Cypress, CA, US) on grapes. The results showed that depending on the deployed spray method, specifically, the swath width used and the flight pattern flown, the UAV spray application could achieve 2.0 to $4.5 \mathrm{hm}^{2} / \mathrm{h}$ work rates while applying the volume of 14.0 to $39.0 \mathrm{~L} / \mathrm{hm}^{2}$. The spray deposition on the grape foliage increased with the applied volume rate. Zhang et al. ${ }^{[04]}$ explored the droplet penetration of spraying citrus trees with different shapes with a UAV. The results showed that the UAV spraying could obtain a better droplet distribution at a $1.0 \mathrm{~m}$ working height. Chen et al. ${ }^{[105]}$ studied the influence of the spraying parameters of a six-rotor UAV on the droplet deposition distribution in the citrus canopy. The results showed the factors that affected the density of the deposited droplets were in the order of flight speed, flight height, and nozzle flow rate, and the preferred spraying operation parameters for small plant protection UAVs were a $2.5 \mathrm{~m}$ flight height, a $4.0 \mathrm{~m} / \mathrm{s}$ flight speed and a $1.0 \mathrm{~L} / \mathrm{min}$ nozzle flow rate.

Table 2 Summary of optimal operating parameters for different types of UAVs from published studies

\begin{tabular}{|c|c|c|c|c|c|c|c|c|c|}
\hline Type of aircraft & Crop & $\begin{array}{l}\text { Volume of } \\
\operatorname{tank} / \mathrm{L}\end{array}$ & $\begin{array}{l}\text { Flight height } \\
\text { tested } / \mathrm{m}\end{array}$ & $\begin{array}{l}\text { Optimal flight } \\
\text { height } / \mathrm{m}\end{array}$ & $\begin{array}{l}\text { Flight speed tested } \\
\qquad / \mathrm{m} \cdot \mathrm{s}^{-1}\end{array}$ & $\begin{array}{l}\text { Optimal flight } \\
\text { speed } / \mathrm{m} \cdot \mathrm{s}^{-1}\end{array}$ & $\begin{array}{c}\text { Spray } \\
\text { swath } / \mathrm{m}\end{array}$ & $\mathrm{CV} / \%$ & Source \\
\hline WPH642 helicopter & rice & 8 & $1,2,3,4$ & 2 & $1.5,2,2.5$ & 1.5 & N/A & N/A & Zhang et al. ${ }^{[99]}$ \\
\hline N-3 helicopter & maize & 20 & $5,7,9$ & 7 & 3 & N/A & 7.0 & 25 & Qin et al. ${ }^{[17]}$ \\
\hline Rmax single-rotor UAV & grape & 26 & $3-4$ & N/A & 5.56 & N/A & $\begin{array}{l}4.8 \\
7.2\end{array}$ & N/A & $\begin{array}{l}\text { Giles and } \\
\text { Billing }{ }^{[103]}\end{array}$ \\
\hline HyB-15L single-rotor UAV & rice & 15 & $0.8,1.5$ & 1.5 & 3,5 & 5 & $\mathrm{~N} / \mathrm{A}$ & 23 & Qin et al. ${ }^{[18]}$ \\
\hline P-20 quad-rotor UAV & rice & 6 & $1-3$ & 2 & $2-6$ & 3.7 & N/A & N/A & Qin et al. ${ }^{[100]}$ \\
\hline $\begin{array}{l}\text { 3W-LWS-Q60S quad-rotor } \\
\text { UAV }\end{array}$ & citrus & 6 & $0.5,1,1.5$ & 1 & 1 & N/A & N/A & $13.4-34.4$ & Zhang et al. ${ }^{[104]}$ \\
\hline TXA-16 six-rotor UAV & citrus & 16 & $1.5,2,2.5$ & 2.5 & $2,4,6$ & 4 & N/A & $\mathrm{N} / \mathrm{A}$ & Chen et al. ${ }^{[105]}$ \\
\hline N-3 helicopter & wheat & 25 & $3.5,5$ & 5 & 4 & $\mathrm{~N} / \mathrm{A}$ & N/A & 33.1 & Qin et al. ${ }^{[42]}$ \\
\hline MG-1 eight-rotor UAV & N/A & 10 & $2,3,4$ & 2 & $1,3,5,7$ & 3 & $5-7$ & $<25$ & Woldt et al. $^{[101]}$ \\
\hline V6A six-rotor UAV & N/A & 5 & $2,3,4$ & 3 & $1,3,5,7$ & 7 & $5-7$ & $<25$ & Woldt et al. ${ }^{[101]}$ \\
\hline Jifei P20 quad-rotor UAV & cotton & $6,8,10$ & $1.5,2$ & 2 & $1-8$ & $\mathrm{~N} / \mathrm{A}$ & $1.5-3$ & $50.3-178.1$ & Lou et al. ${ }^{[19]}$ \\
\hline
\end{tabular}

\subsection{Pesticide drift models for UAV spraying}

The safe, efficient and efficacious use of pesticides requires the management of pesticide drift and deposition. The sensitivity of drift to numerous factors, including atmospheric conditions and application equipment, makes it difficult to field test the full range of possible meteorological application scenarios. Modeling provides a coherent framework for evaluating the potential risks of spray operations and the potential effectiveness of possible mitigation options ${ }^{[106,107]}$. Many researchers have attempted to model spray drift to predict the downwind behavior of released sprays and assess their potential environmental impact.

There are two approaches to aerial spray models: empirical and mechanistic. The empirical models do not account for any physical basis and are generally applicable only to situations that are very similar to those for which they are developed. Mechanistic models based on Gaussian dispersion equations and particle tracking models (Lagrangian particle trajectory (AGDISP)) provide the means to use the available information databases and to understand and quantify the processes that influence the spray behavior. Gaussian modeling is a classical approach that is used 
in atmospheric dispersion modeling of releases from tall stacks and line, area, and volume sources and is well suited for modeling moderately long-range drift $(0.5 \mathrm{~km})$ and simulating the effects of atmospheric stability. However, the Gaussian approach does not provide much resolution in the representation of equipment and near-field dynamics for the flow field near the aircraft. Lagrangian models track a cohort of droplets in a given drop size category and overlay a random component on the movement of the droplets to account for atmospheric turbulence ${ }^{[108]}$. Table 3 summarizes and compares these models by listing their primary characteristics.

Table 3 Summary of aerial spray drift models

\begin{tabular}{|c|c|c|c|}
\hline \multicolumn{2}{|c|}{ Model type } & \multirow{2}{*}{$\begin{array}{l}\text { Shortcomings } \\
\text { applicable only to situations that are very similar to those } \\
\text { for which they are developed }\end{array}$} & \multirow{2}{*}{$\begin{array}{l}\text { Advantages } \\
\text { quantitative analysis and the repetitive comparison of the } \\
\text { relevant factors; wind tunnel research can control conditions }\end{array}$} \\
\hline Empirical model & $\begin{array}{c}\text { Field testing; } \\
\text { Wind tunnel research }\end{array}$ & & \\
\hline \multirow{3}{*}{ Mechanistic model } & CFD & incompatibility & $\begin{array}{l}\text { reproducible results, repeatable and controllable conditions, } \\
\text { rapid, economical and accurate means }\end{array}$ \\
\hline & Gaussian modeling & $\begin{array}{l}\text { does not provide much resolution in the representation of } \\
\text { equipment and near-field dynamics for the flow field near } \\
\text { the aircraft }\end{array}$ & the droplet trajectory analysis \\
\hline & $\begin{array}{l}\text { Lagrangian model } \\
\text { (AGDISP) }\end{array}$ & $\begin{array}{l}\text { (1) only apply to aircraft with a single main rotor; } \\
\text { (2) the flying height and speed must be sufficiently high }\end{array}$ & $\begin{array}{c}\text { well suited for modeling moderately long-range drift }(0.5 \mathrm{~km}) \\
\text { and simulating the effects of atmospheric stability }\end{array}$ \\
\hline
\end{tabular}

\subsubsection{Empirical model}

Research methods on empirical models primarily include field testing and wind tunnel research. Compared with field testing, the wind tunnel environment can accurately control the test conditions, such as the wind speed, airflow direction, temperature, etc. Quantitative analysis and the repetitive comparison of the relevant factors that affect the test results can be conducted in these models.

$\mathrm{Ru}$ et $\mathrm{al}^{[109]}$ conducted droplet spraying drift tests under different airflow and spraying conditions through droplet concentration testing by using a wind tunnel, and they obtained drift distance prediction models under crosswinds. Azizpanah et al. ${ }^{[110]}$ employed an artificial neural network method for predicting the sprayer drift under different tunnel conditions using an image processing technique. Four Levenberg-Marquardt models were developed to correlate the sprayer drift (output parameter) to the input parameters (height, pressure, wind velocity and Dv0.5). Both models predicted the output variables with $R^{2}$ values higher than 0.96. Zhang et al. ${ }^{[11]}$ studied the influences of the nozzle type, spray mixture and wind speed on the spray drift by using a wind tunnel. A multiple non-linear model for statistical drift prediction including four independent, non-correlated variables (target distance, wind speed, nozzle type and chemical type) was established. Zheng et al. ${ }^{[95]}$ analyzed the effects on the droplet deposition rate caused by different UAV operation parameters and established mathematical models of droplet-penetrating coefficients with the UAV operation parameters for corn at all growth stages. The determination coefficients $\left(R^{2}\right)$ of all the models were greater than 0.90 and the average relative errors were within $20 \%$. Wang et al. $^{[112]}$ studied the droplet deposition distribution by UAV spraying as performed in a wind tunnel, and the influence mechanism of parameters such as the airflow field parameters, droplet properties, and relative positions of the nozzle target on the distribution of the droplet deposition was discussed. The test results showed that the wind speed, flying height and droplet diameter were the most significant factors, the rotor airflow was a significant factor, and the nozzle spraying angle was not significant enough to affect the deposition distribution. A multivariate linear prediction model was obtained by analysis of variance, and the $\mathrm{R}^{2}$ of the prediction model was 0.94 . Wang et al. ${ }^{[113]}$ studied the spray drift and deposition using a QuanFeng120 UAV in a pineapple field under various different meteorological conditions. According to the downwind spray drift curve, the nonlinear equations of the same type were fitted under the four operating conditions of the UAV. It was suggested that the UAV operating height should be below $2.5 \mathrm{~m}$ when spraying in pineapple plants and the wind speed should be $5 \mathrm{~m} / \mathrm{s}$ or less during actual operation. 3.4.2 Computational Fluid Dynamics (CFD) model

The CFD model provides whole-flow field data, fast and reproducible results, repeatable and controllable conditions, reliable data, and rapid, economical and accurate means, but at the expense of incompatibility ${ }^{[114]}$.

Fesal et al. ${ }^{[14]}$ proposed a CFD Lagrangian model, which was able to predict the aerial spray dispersion using a flat fan atomizer at released height from 3.7 to $4.7 \mathrm{~m}$ at a constant $30 \mathrm{~m} / \mathrm{s}$ aircraft speed. Omar et al. ${ }^{[115]}$ studied the spray characteristics under different parameters, and a CFD model was developed to predict and simulate the spray droplet transport on the effect of the aircraft speed and nozzle orientation for the distribution of spray droplets at a certain height.

Wang et al. ${ }^{[116]}$ conducted a simulation test to study the droplet deposition characteristics over a range from -1.5 to $4 \mathrm{~m}$ in the downwind direction of the UAV based on multi-feature fusion by using CFD. The simulation boundary conditions and simulation parameters of a 3-dimensional air field space were defined according to the spraying parameters measured from the UAV. The unclearness of the wind field distribution leads to more serious droplet drift problems. The drift and distribution of the droplets, which depend on the airflow distribution characteristics of UAVs and the droplet size of the nozzle, are directly related to the control effect of the pesticide and the crop growth during different growth periods. Parra et al. ${ }^{[117]}$ used CFD to perform a transient analysis of physical variables associated with aerodynamic and water behavior in a UAV for crop spraying and evaluated its impact on the coverage area in the 3D model of the plant.

3.4.3 Using AGDISP models and CHARM for UAV applications

AGDISP is a Lagrangian model that includes a simplified helicopter wake model that transitions from a downwash under a single set of rotor blades to fully rolled-up tip vortices. The AGDISP helicopter model is restrictive in two ways, (1) it can only be applied to aircraft with a single main rotor, and (2) the aircraft flying height and speed must be sufficiently high that the downwash model rolls up into a pair of vortices before the ground impacted by the rotor downwash. These restrictions prevent the existing helicopter model from simulating the behavior of UAV wakes because UAVs often have multiple rotors and fly much closer to the ground and at much slower speeds than helicopters ${ }^{[18]}$.

The CHARM (Comprehensive Hierarchical Aeromechanics Rotorcraft Model) is a self-contained rotor/wake/body 
computational analysis that models the rotorcraft blade aerodynamics and dynamics in hover and forward flight. It is designed with a hierarchical structure to enable a single code to be applicable to a full range of modeling tasks, from the prediction of extremely high-resolution air loads to flight dynamics applications. Several features of this model are particularly advantageous for the real-time prediction of aerial pesticide applications by UAVs. First, CHARM couples a vortex lattice blade model, a free-vortex wake model, and a fast panel fuselage model to model the full aircraft and its wake effects from first principles, including multiple rotors $^{[119]}$. Second, the model has the ability to predict rotor outwash in flight near the ground, and it has been extensively validated through correlation with test data, including data generated by tilt rotors ${ }^{[120]}$. CHARM has been used by the U.S. Navy to model the outwash impact of a military helicopter wakes on ground personnel, and it has been used by the U.S. Army to model the impact of rotor wakes on ordnance trajectories and brownout ${ }^{[121]}$. The current model has also been used for real-time simulations $^{[122]}$.

Teske et al. ${ }^{[118]}$ explored the theoretical behavior of two UAVs (the Dragonfly DP-12 Rhino tandem rotor, DPI UAV Systems, US and the Aeronavics ICON octocopter, Aeronavics Ltd, US) as representatives of UAV size limits in two spraying scenarios of low and high-speed crosswinds. The development of the wake motion and deposition potential was predicted by combining the helicopter technology developed in CHARM with the droplet trajectory analysis in AGDISP. The CHARM+AGDISP model demonstrated the importance of a critical flight speed. This speed acts as an upper limit to the forward speed of the UAV, irrespective of the crosswind or release height (for a given spray boom configuration). The simulation results showed that the spray application effectiveness would be compromised at flight speeds above the critical speed, and Sarri et al. ${ }^{[13]}$ also achieved these results.

\section{Future developments}

The challenges in forecasting the future of UAVs in agriculture are the rapid advancement in current work and the increased development of new systems with the increased integration of new and innovative technologies. While it is acknowledged that the regulatory issues are ever evolving in many countries, there is no denying that UAVs will continue to see increased integration in the agricultural environment.

Like any new technology being applied to an established area, UAVs have the capability to both enhance and disrupt current practices. The current state-of-the-art, as discussed in this paper, demonstrates the many successful uses of UAVs to apply agricultural chemicals. Research continues to be conducted to enhance these technologies and create new technologies to promote the efficient and safe use of pesticides.

\subsection{Downwash airflow field}

Spraying low-volume agrichemicals using UAVs at low flight altitudes differs from conventional manned aerial applications. Downwash airflow produced by UAVs directly determines the movements of spray droplets in space. It is not only the main factor affecting the deposition of the droplets on the target but also the main reason for the droplets to drift away from the target. Most of the current researches in this area focus on the distribution characteristics and effects on the spray performance, but they have issues in the lack of thorough and in-depth research on airflow models, system mechanism, correlation of spraying parameters, accurate measurement methods in field test conditions. Present airflow models are specifically developed for particular types of UAVs, so general and reliable airflow models are needed to be established for a class of UAVs. After the models are established, they need to be examined and verified. However, there are no specific sensors for downwash measurement to show the flowing and distribution in large scales in detail, more research is therefore needed to develop specific sensors to monitor the transfer and the diffusing of UAV downwash. Furthermore, the downwash research needs to be combined with field application. Different crops should be specifically tested and analyzed in different conditions to find the common law of characteristics of the distribution of downwash for a kind of plant.

\subsection{Combined use of big data analytics and UAV technology}

UAV-based remote sensing technologies have advanced rapidly in recent years and have become effective tools for site-specific management in plant protection. They have greatly expanded the application range for monitoring crops to provide high-resolution data when atmospheric, environmental and solar conditions are acceptable. UAV-based spraying platform should be combined with remote sensing which can provide efficient and accurate use of the agrochemical products. However, how to automate the process to analyze hundreds to thousands of images, each covering a small area is a challenge for the application of UAV-based remote sensing technology for plant protection. The integration of artificial intelligence (AI) and UAVs is considered as one of the most promising solutions regarding the development of smart farming as they can be used to enhance technologies, deal with complexity and big data, as well as to provide high accurate and speedy processing. Deep learning algorithms have been broadly applied within the UAV-based remote sensing system such as in feature extraction systems which require great computational resources. Moreover, the advent of the Internet of Things (IoT) can lead to valuable and at the same time economic precision agriculture (PA) applications. PA and smart farming are active fields that produce new opportunities for the future. For example, Vasudevan et al. ${ }^{[123]}$ presented a combined application composed of a UAV and an unmanned ground vehicle (UGV) for monitoring and managing the agriculture crops. The VINEyardROBOT project $^{[124]}$ was to construct an agricultural robot equipped with multiple sensing technologies to monitor water stress, vegetative growth, grape yield and grape composition. More research is needed to combine information and communication technologies, robots, AI, big data, and the IoT with UAVs.

\subsection{Variable-rate spray technology}

Variable-rate spray technology can be applied to spray objects on demand, and it has the greater potential of improving pesticide utilization, reducing pesticide residues and reducing environmental risk. The technology for variable flow rate includes pressure control, variable flow rate nozzles, and PWM control technology. Therefore, the design of nozzles that produce optimal droplet size spectra for mitigation of off-target drift and to provide maximum application efficacy is the first step for the development of intelligent sprayers. These desired size ranges with consistent droplet size distributions require the nozzles to operate within the proper boundaries of their designed pressure. Variable rates called for by the aerial application system might operate these nozzles outside their optimal pressure ranges, making their valid use questionable if a wider range of flow rate is required. This would not be a problem for "on-off" variable control. Variable sprays should also use control technology to improve the 
performance of low-cost devices and equipment and develop specific algorithms to build a relation model between the influence factors and spray volume.

\subsection{Drift reduction technologies for UAV spraying}

Several studies have demonstrated the spray deposition patterns in various crops. While these studies can serve as a good starting point for guiding an operator on how to make an application, detailed information is lacking to help the applicator configure specific UAVs. More research is needed on the role of spray droplet size on spray deposition and drift. As more and more agricultural land is treated with UAVs, the chance of agrichemical drift impacting adjacent crops and other sensitive areas will also increase. Additional research on the interactions of nozzle placement and spray deposition and drift in relation to the aircraft rotor(s) will provide valuable information to manufacturers and operators.

As the number of agrichemicals being applied by UAVs increases around the world, chemical manufacturers will likely start formulating products specifically for UAVs. Most chemical formulations are designed to be diluted in water for most ground and aerial applications. These dilutions required that products be formulated with a combination of stabilizers, emulsifiers, and other adjuvants. Products designed for UAV applications would be formulated to be applied straight from the container with no mixing required since any water added to the chemical would impact the working capacity of the UAV. Eliminating the need to mix would also reduce worker exposure. There will be a need to research how different active ingredients in these formulated products perform since all previous research has used diluted sprays.

Pesticide drift models for UAV spraying provide a coherent framework for evaluating the potential risks of spray operations and the potential effectiveness of possible mitigation options. With the droplet-sizing facilities used in the testing and other spray technologies being updated, more research is needed to enhance these technologies and create new technologies for accuracy. Additional atomization data and models should integrate the growing number of new, formulated active ingredient products as well as the growing number of spray adjuvants used in the real world. Additional guidance on drift potential as a function of the predicted droplet size and a given UAV type and environmental conditions is required to further guide the best management decisions for UAV spray applications.

\subsection{Swarm UAV cooperative technology}

Single UAV is characterized by its limited flight endurance, and it cannot complete all the tasks in large crops. However, the swarm UAV cooperative technology has the potential to increase UAV usage and efficiency. As of May 2019, the current record for the most drones operated at one time stands at 1374 by the Ehang Corporation (www.ehang.com, 21 May 2019) for a light show in Xi'an, China. With this level of coordination and control, it is easy to forecast how this technology could be used in agricultural applications. Using multiple UAVs (5-20) to treat a field would increase the amount of land sprayed per day and the required automated and coordinated flight operations. These systems currently exist, but they are being held back in some countries due to regulations. Many of the regulations revolve around the need/requirement for a person to remain in control of the aircraft at all times. Based on the author's experience, the time at which a UAV crash is most likely to happen is when the human operator has control or suddenly takes control of the UAV. The human attention span is limited and subject to distractions such as cell phone calls or notifications, a new object entering the field of vision, and many other factors. Once a UAV or multiple UAVs have been programmed, they will execute that program with a level of precision beyond that of any human controller.

\section{Conclusions}

While UAVs are a fairly recent addition to the crop protection tools available to farmers and applicators around the world, considerable progress has been and is being made in optimizing the use of systems to apply crop protection chemicals. Assessments of UAV spray technology through field trials for spray quality, efficacy, and safety will considerably influence the development of UAV spray applications. Pesticide canopy penetration, droplet deposition and coverage, and spray drift control are priorities to evaluate the efficiency and efficacy of the crop protection products applied by UAVs. We are challenged with the lack of applicator experience that is far beyond basic UAV operations but involves a comprehensive understanding of the multiple variables affecting UAV spray quality and pesticide efficacy. Advanced flight control systems, spraying systems, sensing systems, pesticide drift and deposition models and spray mix additives or adjuvants, which permit flight and spray well, require continued development.

\section{Acknowledgements}

The authors gratefully acknowledge the support provided by the National Key Research and Development Program of China (Grant No. 2016YFD0200606; Grant No. 2018YFD0200700), China Agriculture Research System (Grant No. CARS-15-22).

\section{[References]}

[1] Hunter M C, Smith R G, Schipanski M E, Atwood L W, Mortensen D A. Agriculture in 2050: recalibrating targets for sustainable intensification. Bioscience, 2017; 67(4): 386-391.

[2] Yuan L, Bao Z Y, Zhang H B, Zhang Y T, Liang X. Habitat monitoring to evaluate crop disease and pest distributions based on multi-source satellite remote sensing imagery. Optik, 2017; 145: 66-73.

[3] Macfadyen S, McDonald G, Hill M P. From species distributions to climate change adaptation: knowledge gaps in managing invertebrate pests in broad-acre grain crops. Agric Ecosyst Environ, 2018; 253: 208-219.

[4] Lan Y B, Chen S D. Current status and trends of plant protection UAV and its spraying technology in China. Int J Precisi Agric Aviat, 2018; 1(1): 1-9.

[5] Hilz E, Vermeer A W P. Spray drift review: the extent to which a formulation can contribute to spray drift reduction. Crop Prot, 2013; 44: 75-83.

[6] Oerke E C. Crop losses to pests. J Agric Sci, 2006; 144(1): 31-43.

[7] Lan Y B, Chen S D, Fritz B K. Current status and future trends of precision agricultural aviation technologies. Int $\mathrm{J}$ Agric \& Biol Eng, 2017; 10(3): 1-17.

[8] He X K, Bonds J, Herbst A, Langenakens J. Recent development of unmanned aerial vehicle for plant protection in East Asia. Int J Agric \& Biol Eng, 2017; 10(3): 18-30

[9] Mogili U R, Deepak B B V L. Review on application of drone systems in precision agriculture. Procedia Comput. Sci, 2018; 133: 502-509.

[10] Huang Y B, Thomson S J, Hoffmann W C, Lan Y B, Fritz B K Development and prospect of unmanned aerial vehicle technologies for agricultural production management. Int J Agric \& Biol Eng, 2013; 6(3): $1-10$.

[11] Liao J, Zang Y, Zhou Z Y, Luo X W. Quality evaluation method and optimization of operating parameters in crop aerial spraying technology. Transactions of the CSAE, 2015; 31(Supp.2): 38-46. (in Chinese)

[12] Chen S D, Lan Y B, Li J Y, Xu X J, Wang Z G, Peng B. Evaluation and test of effective spraying width of aerial spraying on plant protection UAV. Transactions of the CSAE, 2017; 33(7): 82-90. (in Chinese)

[13] Sarri D, Martelloni L, Rimediotti M, Lisci R, Lombardo S, Vieri M. Testing a multi-rotor unmanned aerial vehicle for spray application in high slope terraced vineyard. J Agric Eng, 2019; 50(1): 38-47. 
[14] Fritz B K. Role of atmospheric stability in drift and deposition of aerially applied sprays-preliminary results. 2004 ASAE Annual Meeting, Ottawa, CA, 2004; 58:742-755.

[15] Kirk I W, Fritz B K, Hoffmann W C. Aerial methods for increasing spray deposits on wheat heads. 2004 ASAE Annual Meeting, Ottawa, CA, 2004; 58:716-729.

[16] Xue X Y, Tu K, Lan Y B, Qin W C, Zhang L. Effects of pesticides aerial applications on rice quality. Transactions of the CSAM, 2013; 44(12): 94-79. (in Chinese)

[17] Qin W C, Xue X Y, Zhou L X, Zhang S C, Sun Z, Kong W, et al. Effects of spraying parameters of unmanned aerial vehicle on droplets deposition distribution of maize canopies. Transactions of the CSAE, 2014; 30(5): 50-56. (in Chinese)

[18] Qin W C, Qiu B J, Xue X Y, Chen C, Xu Z F, Zhou Q Q. Droplet deposition and control effect of insecticides sprayed with an unmanned aerial vehicle against plant hoppers. Crop Protection, 2016; 85: 79-88.

[19] Lou Z X, Xin F, Han X Q, Lan Y B, Duan T Z, Fu W. Effect of unmanned aerial vehicle flight height on droplet distribution, drift and control of cotton aphids and spider mites. Agronomy, 2018; 8(9): 187. doi: 10.3390/argonomy8090187.

[20] Richardson B, Rolando C A, Kimberley M O, Strand T M. Spray application efficiency from a multi-rotor unmanned aerial vehicle configured for aerial pesticide application. Trans ASABE, 2019; 62(6): 1447-1453.

[21] Chen H B, Fritz K B, Lan Y B, Zhou Z Y, Zheng J F. An overview of spray nozzles for plant protection from manned aircrafts: Present research and prospective. Int J Precis Agric Aviat, 2020; 3(2): 1-12.

[22] Zhang X Q, Liang Y J, Qin Z Q, Li D W, Wei C Y, Wei J J, et al. Application of multi-rotor unmanned aerial vehicle application in management of stem borer (Lepidoptera) in sugarcane. Sugar Tech, 2019; 21(5): 847-852.

[23] Li H, He Y J, Qin C B, Liu D Q, Zhang K F. Ecological analysis on spray performance of multi-rotor unmanned aerial sprayer in soybean field. Ekoloji, 2019; 28(107): 4573-4579.

[24] Giles D K. Use of remotely piloted aircraft for pesticide applications. Outlook Pest Mgmt, 2016; 27(5): 213-216.

[25] Zhu H, Lan Y B, Wu W F, Hoffmann W C, Huang Y B, Xue X Y, et al. Development of a PWM precision spraying controller for UAV. J Bionic Eng, 2010; 7(3): 276-283.

[26] Xu B, Chen L P, Tan Y, Xu M. Path planning based on minimum energy consumption for plant protection UAVs in sorties. Trans CSAM 2015; 46(11): 36-42. (in Chinese)

[27] Xue X Y, Lan Y B, Sun Z, Chang C, Hoffmann W C. Develop an unmanned aerial vehicle based automatic aerial spraying system. Comput Electron Agric, 2016; 128: 58-66.

[28] Wang Y, Chen H T, Li H C. 3D path planning approach based on gravitational search algorithm for sprayer UAV. Transactions of the CSAM, 2018; 49(2): 28-33. (in Chinese)

[29] Fritz B K, Hoffmann W C, Lan Y B. Evaluation of the EPA drift reduction technology (DRT) low-speed wind tunnel protocol. J ASTM Int, 2009; 6(4): 12.

[30] Thomson S J, Womac A R, Mulrooney J E. Reducing pesticide drift by considering propeller rotation effects from aerial application near buffer zones. Sustain Agric Res, 2013; 2(3): 41-51.

[31] Yang Z L, Qi L J, Wu Y L. Influence of UAV rotor down-wash airflow for droplet penetration. 2018 ASAE Annual Meeting, Michigan, USA, 2018.

[32] Zhou Y E, Xu G H, Shi Y J. High-resolution numerical research on formation and evolution mechanism of rotor blade tip vortex. Acta Aeronaut. Astronaut. Sin., 2017; 38(7): 43-53. (in Chinese)

[33] Li J Y, Lan Y B, Shi Y Y. Research progress on airflow characteristics and field pesticide application system of rotary-wing UAV. Trans CSAE, 2018; 34(12): 104-118. (in Chinese)

[34] Wang J F, Xu W B, Wen J L, Wang X Y, Luo B T. Numerical simulation on gas-liquid phase flow of large-scale plant protection unmanned aerial vehicle spraying. Trans CSAM, 2017; 48(9): 62-69. (in Chinese)

[35] Xu W B, Wang J F, Wen J L, Wang X Y. Numerical simulation for downwash flow field of large-size plant protection unmanned helicopter hedgehopping. Journal of Jiangsu University, 2017; 38(6): 665-671. (in Chinese)

[36] Zhang S C, Xue X Y, Sun Z, Zhou L X, Jin Y K. Downwash distribution of single-rotor unmanned agricultural helicopter on hovering state. Int $\mathrm{J}$
Agric \& Biol Eng, 2017; 10(5): 14-24.

[37] Chen S D, Lan Y B, Li J Y, Zhou Z Y, Liu A M, Mao Y D. Effect of wind field below unmanned helicopter on droplet deposition distribution of aerial spraying. Int J Agric \& Biol Eng, 2017; 10(3): 67-77.

[38] Yang F B, Xue X Y, Zhang L, Sun Z. Numerical simulation and experimental verification on downwash air flow of six-rotor agricultural unmanned aerial vehicle in hover. Int J Agric \& Biol Eng, 2017; 10(4): 41-53.

[39] Tan F, Lian Q, Liu C L, Jin B K. Measurement of downwash velocity generated by rotors of agriculture drones. INMATEH- Agric Eng, 2018; 55(2): 141-150.

[40] Xue X Y, Tu K, Qin W C, Lan Y B, Zhang H H. Drift and deposition of ultra-low altitude and low volume application in paddy field. Int J Agric \& Biol Eng, 2014; 7(4): 23-28.

[41] Chen S D, Lan Y B, Li J Y, Zhou Z Y, Liu A M, Xu X J. Comparison of the pesticide effects of aerial and artificial spray applications for rice. Journal of South China Agricultural University, 2017; 38(4): 103-109. (in Chinese)

[42] Qin W C, Xue X Y, Zhang S M, Gu W, Wang B K. Droplet deposition and efficiency of fungicides sprayed with small UAV against wheat powdery mildew. Int J Agric \& Biol Eng, 2018; 11(2): 27-32.

[43] Gao Y Y, Zhang Y T, Zhang N, Niu L, Zheng W W, Yuan H Z. Primary studies on spray droplets distribution and control effects of aerial spraying using unmanned aerial vehicle (UAV) against wheat midge. Crops, 2013 2: 139-142. (in Chinese)

[44] Tang Q, Zhang R R, Chen L P, Xu M, Yi T C, Zhang B. Droplets movement and deposition of an eight-rotor agricultural UAV in downwash flow field. Int J Agric \& Biol Eng, 2017; 10(3): 47-56.

[45] Mayeed M S, Darveau G. Designing an Unmanned Aerial Vehicle for specific aerial applications of insecticides and herbicides. In: ASME 2016 International Mechanical Engineering Congress and Exposition, Arizona, USA, 2016; 14: 8. doi: 10.1115/IMECE2016-65936.

[46] Wang C L, He X K, Wang X N, Wang Z C, Wang S L, Li L L, et al Testing method and distribution characteristics of spatial pesticide spraying deposition quality balance for unmanned aerial vehicle. Int $\mathrm{J}$ Agric \& Biol Eng, 2018; 11(2): 18-26.

[47] Yang F B, Xue X Y, Cai C, Zhou Q Q. Effect of down wash airflow in hover on droplet motion law for multi-rotor unmanned plant protection machine. Trans CSAE, 2018; 34(2): 64-73. (in Chinese)

[48] Yang F B, Xue X Y, Cai C, Sun Z, Zhou Q Q. Numerical simulation and analysis on spray drift movement of multirotor plant protection unmanned aerial vehicle. Energies, 2018; 11(9): 2399. doi: 10.3390/en11092399.

[49] Yang Z L, Ge L Z, Qi L J, Cheng Y F, Wu Y L. Influence of UAV rotor down-wash airflow on spray width. Transactions of the CSAM, 2018; 49(1): 116-122. (in Chinese)

[50] Zheng Y J, Yang S H, Liu X X, Wang J, Norton T, Chen, J, et al. The computational fluid dynamic modeling of downwash flow field for a six-rotor UAV. Front. Agr. Sci. Eng., 2018; 5(2): 159-167.

[51] Shi Q, Mao H, Guan X. Numerical simulation and experimental verification of the deposition concentration of an unmanned aerial vehicle. Appl Eng Agric, 2019; 35(3): 367-376.

[52] Wen S, Han J, Ning Z H, Lan Y B, Yin X C, Zhang J T, et al. Numerical analysis and validation of spray distributions disturbed by quad-rotor drone wake at different flight speeds. Comput Electron Agric, 2019; 166: 10536.

[53] Hunt E R, Daughtry C S. What good are unmanned aircraft systems for agricultural remote sensing and precision agriculture. Int J Remote Sens, 2018; 39(15-16): 5345-5376.

[54] Maes W H, Steppe K. Perspectives for remote sensing with unmanned aerial vehicles in precision agriculture. Trends Plant Sci, 2018; 24(2): 152-164.

[55] Aasen H, Honkavaara E, Lucieer A, Zarco-Tejada P. Quantitative remote sensing at ultra-high resolution with UAV spectroscopy: A review of sensor technology, measurement procedures, and data correction workflows. Remote Sens, 2018; 10(7): 1091. doi: 10.3390/rs10071091.

[56] Yin N H, Liu R A, Zeng B B, Liu N. A review: UAV-based remote sensing. IOP Conference Series: Materials Science and Engineering, Shanghai, China, 2019; 490: 062014. doi: 10.1088/1757-899X/490/6/ 062014.

[57] Lan Y B, Deng X L, Zeng G L. Advances in diagnosis of crop diseases, pests and weeds by UAV remote sensing. Smart Agric, 2019; 1(2): 1-19.

[58] Rango A, Laliberte A, Herrick J E, Winters C, Havstad K, Steele, C, et al. Unmanned aerial vehicle-based remote sensing for rangeland assessment, 
monitoring, and management. J Appl Remote Sens, 2009; 3(1): 033542. doi: 10.1117/1.3216822.

[59] Wang P, Luo X W, Zhou Z Y, Zang Y, Hu L. Key technology for remote sensing information acquisition based on micro UAV. Transactions of the CSAE, 2014; 30(18): 1-12. (in Chinese)

[60] Psirofonia P, Samaritakis V, Eliopoulos P, Potamitis I. Use of unmanned aerial vehicles for agricultural applications with emphasis on crop protection: three novel case-studies. Int J Agric Sci Technol, 2017; 5: 30-39.

[61] Hunt E R, Rondon S I. Detection of potato beetle damage using remote sensing from small unmanned aircraft systems. J Appl Remote Sens, 2017; 11(2): 026013. doi: 10.1117/1.JRS.11.026013.

[62] Albetis J, Duthoit S, Guttler F, Jacquin A, Goulard M, Poilvé H, et al. Detection of Flavescence dorée grapevine disease using unmanned aerial vehicle (UAV) multispectral imagery. Remote Sensing, 2017; 9(4): 308. doi: 10.3390/rs9040308.

[63] Ha J G, Moon H, Kwak J T, Hassan S I, Dang M, Lee O N, et al. Deep convolutional neural network for classifying Fusarium wilt of radish from unmanned aerial vehicles. J Appl Remote Sens, 2017; 11(4): 042621. doi: 10.1117/1.JRS.11.042621.

[64] Tetila E C, Machado B B, Belete N A, Guimarães D A, Pistori H. Identification of soybean foliar diseases using unmanned aerial vehicle images. IEEE Geoscience and Remote Sensing Letters, 2017; 14(12): 2190-2194.

[65] Alexandridis T, Tamouridou A A, Pantazi X E, Lagopodi A, Kashefi J, Ovakoglou G, et al. Novelty detection classifiers in weed mapping: Silybum marianum detection on UAV multispectral images. Sens, 2017; 17(9): 2007 . doi: 10.3390/s17092007.

[66] Morley C G, Broadley J, Hartley R, Herries D, MacMorran D, McLean I G. The potential of using unmanned aerial vehicles (UAVs) for precision pest control of possums (Trichosurus vulpecula). Rethinking Ecology, 2017; 2: 27-39.

[67] Castaldi F, Pelosi F, Pascucci S, Casa R. Assessing the potential of images from unmanned aerial vehicles (UAV) to support herbicide patch spraying in maize. Precis Agric, 2017; 18(1): 76-94.

[68] Tamouridou A, Alexandridis T, Pantazi X, Lagopodi A, Kashefi J, Kasampalis D, et al. Application of multilayer perceptron with automatic relevance determination on weed mapping using UAV multispectral imagery. Sensors, 2017; 17(10): 2307 . doi: 10.3390/s17102307.

[69] Pantazi X E, Tamouridou A A, Alexandridis T K, Lagopodi A L, Kashefi J, Moshou D. Evaluation of hierarchical self-organising maps for weed mapping using UAS multispectral imagery. Comput Electron Agric, 2017; 139: 224-230.

[70] Sa I, Popović M, Khanna R, Chen Z, Lottes P, Liebisch F, et al. WeedMap: A large-scale semantic weed mapping framework using aerial multispectral imaging and deep neural network for precision farming. Remote Sensing, 2018; 10(9): 1423. doi: 10.3390/rs10091423.

[71] De Castro A I, Torres-Sánchez J, Peña J M, Jiménez-Brenes F M, Csillik O, López-Granados F. An automatic random forest-OBIA algorithm for early weed mapping between and within crop rows using UAV imagery. Remote Sensing, 2018; 10(2): 285 . doi: 10.3390/rs10020285.

[72] Huang H S, Deng J Z, Lan Y B, Yang A Q, Deng X L, Wen S, et al. Accurate weed mapping and prescription map generation based on fully convolutional networks using UAV imagery. Sensors, 2018; 18(10): 3299. doi: 10.3390/s18103299.

[73] Huang H S, Deng J J, Lan Y B, Yang A Q, Deng X L, Zhang L. A fully convolutional network for weed mapping of unmanned aerial vehicle (UAV) imagery. PloS One, 2018; 13(4): e0196302. doi: 10.1371/journal.pone.01963023.

[74] Huang H S, Lan Y B, Deng J Z, Yang A Q, Deng X L, Zhang L, et al. A semantic labeling approach for accurate weed mapping of high resolution UAV imagery. Sensors, 2018; 18(7): 2113. doi: 10.3390/s18072113.

[75] Lottes P, Khanna R, Pfeifer J, Siegwart R, Stachniss C. UAV-based crop and weed classification for smart farming. 2017 IEEE International Conference on Robotics and Automation, Singapore, 2017; pp.3024-3031.

[76] Wang S B, Liu H T, Han Y, Chen J, Pan Y, Cao Y, et al. Low-altitude remote sensing based on convolutional neural network for weed classification in ecological irrigation area. IFAC Papers OnLine, 2018; 51(17): 298-303.

[77] Wang Z, Chu G K, Zhang H J, Liu S X, Huang X C, Gao F R, et al. Identification of diseased empty rice panicles based on Haar-like feature of UAV optical image. Trans CSAE, 2018; 34(20): 73-82. (in Chinese)

[78] Huang H S, Deng J Z, Lan Y B, Yang A, Deng X L, Zhang L, et al. A two-stage classification approach for the detection of spider mite-infested cotton using UAV multispectral imagery. Remote Sensing Letters, 2018; 9(10): 933-941.

[79] Vanegas F, Bratanov D, Powell K, Weiss J, Gonzalez F. A novel methodology for improving plant pest surveillance in vineyards and crops using UAV-based hyperspectral and spatial data. Sensors, 2018; 18(1): 260. doi: $10.3390 / \mathrm{s} 18010260$

[80] Zhao X Y, Zhang J, Zhang D Y, Zhou X G, Liu X H, Xie J. Comparison between the effects of visible light and multispectral sensor based on low-altitude remote sensing platform in the evaluation of rice sheath blight Spectrosc Spect Anal, 2019; 39(4): 1192-1198. (in Chinese)

[81] Lan Y B, Zhu Z H, Deng X L, Lian B Z, Huang J Y, Huang Z X, et al Monitoring and classification of citrus Huanglongbing based on UAV hyperspectral remote sensing. Transactions of the CSAE, 2019; 35(3): 92-100. (in Chinese)

[82] Su J Y, Liu C J, Hu X P, Xu X M, Guo L, Chen W H. Spatio-temporal monitoring of wheat yellow rust using UAV multispectral imagery. Comput Electron Agric, 2019; 167: 10503. doi: 10.1016/ j.compag.2019.105035.

[83] Lan Y B, Thomson S J, Huang Y B, Hoffmann W C, Zhang H H. Current status and future directions of precision aerial application for site-specific crop management in the USA. Comput Electron Agric, 2010 74(1): 34-38.

[84] Wang L, Lan Y B, Hoffmann W C, Fritz B K, Chen D, Wang S M. Design of variable spraying system and influencing factors on droplets deposition of small UAV. Transactions of the CSAM, 2016; 47(1): 15-22. (in Chinese)

[85] Wang L H, Gan H M, Yue X J, Lan Y B, Wang J, Liu Y X, et al. Design of a precision spraying control system with unmanned aerial vehicle based on image recognition. Journal of South China Agricultural University, 2016; 37(6): 23-30. (in Chinese)

[86] Wang D S, Zhang J X, Li W, Xiong B, Zhang S L, Zhang W Q. Design and test of dynamic variable spraying system of plant protection UAV. Transactions of the CSAM, 2017; 48(5): 86-93. (in Chinese)

[87] Wen S, Zhang Q Y, Deng J Z, Lan Y B, Yin X C, Shan J. Design and experiment of a variable spray system for unmanned aerial vehicles based on PID and PWM Control. Appl Sci, 2018; 8(12): 2482 . doi 10.3390/aapp8122482.

[88] Lian Q, Tan F, Fu X M, Zhang P, Liu X, Zhang W. Design of precision variable-rate spray system for unmanned aerial vehicle using automatic control method. Int J Agric \& Biol Eng, 2019; 12(2): 29-35.

[89] Wen S, Zhang Q Y, Yin X C, Lan Y B, Zhang J T, Ge Y F. Design of plant protection UAV variable spray system based on neural networks. Sens, 2019; 19(5): 1112. doi: 10.3390/s19051112.

[90] Campos J, Llop J, Gallart M, García-Ruiz F, Gras A, Salcedo R, et al. Development of canopy vigour maps using UAV for site-specific management during vineyard spraying process. Precis Agric, 2019; 20(6) 1136-1156.

[91] Hunter J E, Gannon T W, Richardson R J, Yelverton F, Leon R G. Integration of remote-weed mapping and an autonomous spraying unmanned aerial vehicle for site-specific weed management. Pest Manag Sci, 2020; 76(4): 1386-1392.

[92] Zhang S, Xue X S, Qin W, Sun Z, Ding S, Zhou L. Simulation and experimental verification of aerial spraying drift on N-3 unmanned spraying helicopter. Trans CSAE, 2015; 31(3): 87-93. (in Chinese)

[93] Zhou L P, He Y. Simulation and optimization of multi spray factors in UAV. 2016 ASABE Annual International Meeting, Florida, USA, 2016.

[94] Zhang H C, Zheng J Q, Zhou H P, Dorr, G J. Droplet deposition distribution and off-target drift during pesticide spraying operation. Transactions of the CSAM, 2017; 48(8): 114-122. (in Chinese)

[95] Zheng Y J, Yang S H, Zhao C J, Chen L P, Lan Y B, Tan Y. Modelling operation parameters of UAV on spray effects at different growth stages of corns. Int J Agric \& Biol Eng, 2017; 10(3): 57-66.

[96] Wang X N, He X K, Wang C L, Wang Z C, Li L L, Wang S L, et al Spray drift characteristics of fuel powered single-rotor UAV for plant protection. Transactions of the CSAE, 2017; 33(1): 117-123. (in Chinese)

[97] Liao J, Zang Y, Luo X W, Zhou Z Y, Lan Y B, Zang Y, et al. Optimization of variables for maximizing efficacy and efficiency in aerial spray application to cotton using UASs. Int J Agric \& Biol Eng, 2019; 12(2): 10-17.

[98] Kang T G, Lee C S, Choi D K, Jun H J, Koo Y M, Kang T H. Development of aerial application system attachable to unmanned helicopter-basic spraying characteristics for aerial application system. J 
Biosyst Eng, 2010; 35(4): 215-223.

[99] Zhang J, He X K, Song J L, Zeng A J, Liu Y J, Li X F. Influence of spraying parameters of unmanned aircraft on droplets deposition. Transactions of the CSAM, 2012; 43(12): 94-96. (in Chinese)

[100] Qin W C, Xue X Y, Zhang S C, Gu W, Chen C. Optimization and test of spraying parameters for P20 multi-rotor electric unmanned aerial vehicle based on response surface method. Journal of Jiangsu University, 2016; 37(5): 548-555. (in Chinese)

[101] Woldt W, Martin D, Lahteef M, Kruger G, Wright R, McMechan J, et al. Field evaluation of commercially available small unmanned aircraft crop spray systems. 2018 ASABE Annual International Meeting, Michigan, USA, 2018; pp.1-15.

[102] Hunter J E, Gannon T W, Richardson R J, Yelverton F, Leon R G. Coverage and drift potential associated with nozzle and speed selection for herbicide applications using an unmanned aerial sprayer. Weed Technol, 2020; 34(2): 235-240.

[103] Giles D, Billing R. Deployment and performance of a UAV for crop spraying. Chem Eng Trans, 2015; 44: 307-312.

[104] Zhang P, Deng L, Lyu Q, He S L, Yi S L, Liu Y D, et al. Effects of citrus tree-shape and spraying height of small unmanned aerial vehicle on droplet distribution. Int J Agric \& Biol Eng, 2016; 9(4): 45-52.

[105] Chen S D, Lan Y B, Zhou Z Y, Liao J, Zhu Q Y. Effects of spraying parameters of small protection UAV on droplets deposition distribution in citrus canopy. Journal of South China Agricultural University, 2017; 38(5): 97-102. (in Chinese)

[106] Teske M E, Bowers J F, Rafferty J E, Barry J W. FSCBG: An aerial spray dispersion model for predicting the fate of released material behind aircraft. Environ Toxicol Chem, 1993; 12(3): 453-464.

[107] Teske M E, Bird S L, Esterly D M, Curbishley T B, Ray S L, Perry S G. AgDrift ${ }^{\circledR}$ : A model for estimating near-field spray drift from aerial applications. Environ Toxicol Chem, 2002; 21(3): 659-671.

[108] Teske M E, Thistle H W, Schou W C, Miller P C H, Strager J M, Richardson B, et al. A review of computer models for pesticide deposition prediction. Transactions of the ASABE, 2011; 54(3): 789-801.

[109] Ru Y, Zhu C Y, Bao R. Spray drift model of droplets and analysis of influencing factors based on wind tunnel. Transactions of the CSAM, 2014; 45(10): 66-72. (in Chinese)

[110] Azizpanah A, Rajabipour A, Alimardani R, Kheiralipour K, Mohammadi V. Precision spray modeling using image processing and artificial neural network. Agricultural Engineering International: CIGR Journal, 2015; 17(2): 65-74

[111] Zhang H C, Gary D, Zheng J Q, Zhou H P, Yu J. Wind tunnel experiment and regression model for spray drift. Trans CSAE, 2015; 31(3): 94-100. (in Chinese)

[112] Wang L, Chen D, Yao Z, Ni X D, Wang S M. Research on the prediction model and its influencing factors of droplet deposition area in the wind tunnel environment based on UAV spraying. IFAC Papers OnLine, 2018 51(17): 274-279.

[113] Wang J, Lan Y B, Zhang H H, Zhang Y L, Wen S, Yao W X, et al. Drift and deposition of pesticide applied by UAV on pineapple plants under different meteorological conditions. Int J Agric Biol Eng, 2018; 11(6): $5-12$.

[114] Fesal S N M, Fawzi M, Omar Z. A numerical analysis of flat fan aerial crop spray. 2017 IOP Conference Series: Materials Science and Engineering, Songhkla, Thailand, 2017; 243(1): 012044. doi: 10.1088/1757-899X/243/1/012044.

[115] Omar Z, Qiang K Y, Mohd S, Rosly N. CFD simulation of aerial crop spraying. 2016 IOP Conference Series: Materials Science and Engineering, Melaka, Malaysia, 2016; 160(1): 012028. doi: 10.1088/1757-899X/160/1/012028.

[116] Wang L, Chen D, Zhang M C, Wang Y, Yao Z, Wang S M. CFD simulation of low-attitude droplets deposition characteristics for UAV based on multi-feature fusion. IFAC Papers OnLine, 2018; 51(17): 648-653.

[117] Parra H G, Morales V D A, Garcia E E G. Multiphase CFD simulation of photogrammetry 3D model for UAV crop spraying. In: New Knowledge in Information Systems and Technologies. Switzerland: Springer, 2019; 930: 812-822.

[118] Teske M E, Wachspress D A, Thistle H W. Prediction of aerial spray release from UAVs. Trans ASABE, 2018; 61(3): 909-918.

[119] Wachspress D A, Yu K, Saberi H A, Hasbun M J, Ho J C, Yeo H. Helicopter rotor airload predictions with a comprehensive rotorcraft analysis. Proc. 68th Annual Forum of the American Helicopter Society, Texas, USA, 2012

[120] Keller J D, Wachspress D A. Validation of the CHARM aerodynamic module for engineering and piloted simulation of next-generation tilt rotor aircraft. Ewing, NJ: Continuum Dynamics, Inc. 2012; Report No. 1203.

[121] Wachspress D A, Whitehouse G R, Keller J D, Yu K, Gilmore P, Dorsett $\mathrm{M}$, et al. A high-fidelity brownout model for flight simulations and trainers. Proc. 65th Annual Forum of the American Helicopter Society, Texas, USA, 2009; 1: 278-301.

[122] Wachspress D A, Keller J D, Quackenbush T R, Whitehouse G R, Yu K. High-fidelity rotor aerodynamic module for real-time rotorcraft flight simulation. Proc. 64th Annual forum of the American helicopter society, Montreal, Canada, 2008; 64(1): 288.

[123] Vasudevan A, Kumar D A, Bhuvaneswari N S. Bhuvaneswari, Precision farming using unmanned aerial and ground vehicles. 2016 IEEE Technological Innovations in ICT for Agriculture and Rural Development (TIAR), Chennai, India, 2016; 146-150.

[124] VineyardROBOT Project. Available: https://cordis.europa.eu/ project/rcn/111031/factsheet/it. Accessed on [2020-01-07]. 